\title{
Free Vibration and Dynamic Response Analysis of Stiffened Parabolic Shells using Equivalent Ortho- tropic Shell Parameters
}

\begin{abstract}
Dynamic response and free vibration analysis of stiffened shells having parabolic curvatures, with applications to ships and other similar structures are the main focus of this study. The energy approach is employed to the determination of equivalent orthotropic shell parameters of parabolic stiffened shells. The unstiffened equivalent shell has proper accuracy in predicting free vibration characteristics as well as dynamic response of the main stiffened shell. Reducing the governing equation difficulties with suitable precision in free vibration and dynamic response analyses is the most advantage of replacement of stiffened shells with their unstiffened equivalences.
\end{abstract}

\section{Keywords}

Ship structure; Slamming; Stiffened shell; Parabolic curvature; Dynamic Analysis; Equivalent orthotropic shell.

\author{
Pedram Edalat ${ }^{a}$, \\ Mohammad Reza Khedmati ${ }^{*}$, \\ C. Guedes Soares ${ }^{b}$ \\ ${ }^{\text {a }}$ Faculty of Marine Technology, Amirkabir \\ University of Technology, 424 Hafez Avenue, \\ Tehran 15914, Iran \\ ${ }^{\text {b }}$ Centre for Marine Technology and Engi- \\ neering (CENTEC), Instituto Superior Téc- \\ nico, Technical University of Lisbon, Lisbon, \\ Portugal \\ Received 06Jun 2012 \\ In revised form 09Oct 2012 \\ * Author email: khedmati@aut.ac.ir
}

\section{INTRODUCTION}

Motion of ships in the waves in addition to the operation of their machinery and propelling equipments are the main sources of the forces causing vibration of the hull structures. Slamming is one important phenomenon in which local vibratory loads are induced and exerted on the ship hull structure especially in the forward and aft regions. These locations in the ship hull structure are made of stiffened shell parts with general curvatures. Study of the vibration aspects for the curved stiffened shells inside the ship hull structure is of great importance in ship design process. The problem of vibration for a curved stiffened shell can be reduced to the study of vibration of an equivalent unstiffened orthotropic shell having the same curvature. In line with such an approach, two main methods have been adopted by researchers in order to find the parameters for the equivalent orthotropic curved shell. One approach that is going to be implemented in this paper is based on extracting parameters using this assumption that the natural frequency and mode shape of the stiffened structure are the same as those of the orthotropic structure. In this case the energy method is 


\section{Nomenclature}

$R_{i} \quad$ Radius of curvature in direction of " $?$ "

$d s_{i} \quad$ Length of Shell element in direction of " $? "$

$d A_{i} \quad$ Cross sectional area of element in direction of " $?$ "

$d V^{s h}$

$U, V, W$

$u, v, w$

$u^{l s}, v^{l s}, w^{l s}$

$\theta_{x}, \theta_{s}$

$e_{i}, \gamma_{i j}$

$\sigma_{i}, \tau_{i j}$

$E_{i}, G_{x s}$

$v_{i}$

$e_{i}^{l s}, \gamma_{i j}^{l s}$

$\sigma_{i}^{l s}, \tau_{i j}^{l s}$

$E, G$

$T$

$\Delta t$

Plamming
Volume of element

Displacement function of shell

Displacement function relatedtomi-

dplane of shell

Displacementfunction of centre of longitudinal stiffeners

Rotation function

Strains of Shell

Stresses of shell

Elasticity modules related to orthotropic shell

Poisson's ratio related to orthotropic

shell

Strains related to longitudinal stiffeners

Stresses related to longitudinal stiffe-

ners

Elasticity modules related to isotropic material

Poisson's ratio related to isotropic material

Time in dynamic response $[\mathrm{s}]$

Time interval related to sub-steps in dynamic analysis

Slamming induced pressure
$D_{i}$

$D$

$\rho$

$\rho_{o r}$

L

$b$

C

$t_{p}$

$h_{l s}$

$t_{l s}$

$n_{l s}$

$A_{l s}$

$I_{y y}^{l s}$

$T$

$U_{*}$

$f_{\text {iso }}$

$f_{\text {or }}$

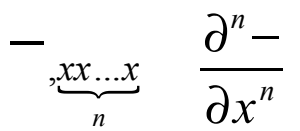

$e_{l s}$ ners
Orthotropic bending stiffness in "?" direction $\frac{t_{p}^{3} E_{i}}{12\left(1-v_{x} v_{s}\right)}$

Isotropic bending stiffness $\frac{t_{p}^{3} E}{12\left(1-v^{2}\right)}$

Isotropic material density

Orthotropic material density

Length of shell

Width of top view of shell

Rise of shell in centre point of transverse direction

Shell thickness

Height of web of longitudinal stiffe-

Thickness of web of longitudinal stiffeners

Number of longitudinal stiffeners

Longitudinal cross sectional area

Longitudinal cross sectional moment of inertia about local axis " $y$ "

Kinetic energy

\section{Strain Energy}

Natural frequency of stiffened isotropic parabolic shell

Natural frequency of equivalent orthotropic shell

Distance between longitudinal neutral axis and shell midplane 
usually employed [1]. The other method is obtaining the parameters based on the concept of smearing the stiffeners inside the shell.

The smearing method has been applied for stiffened plates since the 1970s. Troitsky [2] had reviewed extensively the literature pertaining to rectangular stiffened plates for static, dynamic and stability analysis which are based on orthotropic plate idealization. This method has been further developed and summarized in this field by Szilard [3] in 2004. A comprehensive review has recently been given by $\mathrm{Xu}$ et al. [4] about vibration of stiffened plates. Replacement of stiffened structures with the equivalent unstiffened orthotropic structures has been performed only in the case of stiffened plates [1-7] and curved stiffened shells with constant radius of curvature [8-17]. Srinivasan [16] studied dynamic analysis of stiffened conical shell panels wherein the smearing technique is used for closely spaced stiffeners and the time domain analysis has been done using the mode superposition method. Recently, Luan et al. [17] have applied the smearing method for cross stiffened doubly curved shells with constant radius of curvature. They used flat plate smearing relations with some modifications for finding orthotropic parameters.

As can be well understood, there is not any applicable method available for finding equivalent orthotropic parameters of curved stiffened shell with a general form of curvature and variable radius of curvature. Parabolically curved stiffened shells are one of these types of structures with a wide application range within ship structures.

Free vibration and dynamic response of the stiffened shells incorporating the parabolic curvature is the main subject of this study. Although the finite element method can be implemented for detailed modelling and analysis of any kind of complex structure such as a ship hull, it is very time consuming to model the details of the structures. An analytical technique is established in order to find out the parameters for the equivalent unstiffened shell having the same type of curvature. The technique can be simply applied alone or in combination with the other methods such as the finite element method, to the free vibration and dynamic response analysis of local and global structures as well as complex structures.

\section{DETERMINATION OF EQUIVALENT ORTHOTROPIC SHELL PARAMETERS}

Mode shapes and natural frequencies are considered as the main free vibration characteristics of the structures. Similarity to the mode shapes and equality of the natural frequencies are the main criteria for two systems to be equivalent from free vibration analysis point of view. This similarity, with acceptable precision, leads to the similarity of dynamic responses of the stiffened and equivalent structures. In dynamic analysis of structures there are some available methods that are dependent to the mode shapes. Mode summation method is one of these mode shape-dependent methods.

The structures under consideration in this study include a cylindrical parabolic shell as well as a number of straight stiffening elements. Thus, the governing equations for these types of elements from the geometrical and elasticity points of view are briefly reviewed in Appendix A. Hence in this study, at first the energy equations for the main stiffened shell structure as well as the equivalent unstiffened orthotropic shell structure are written as functions of the displacements. Then the displacement function of the main stiffened shell structure is substituted into the above two sets of energy equations. This will ensure the similarity of the mode shapes for both structures. Afterwards, 
imposing the equality condition between the strain energy and kinetic energy of the two main and equivalent structures and also applying the equality of their natural frequencies, the material properties parameters of the equivalent unstiffened orthotropic shell can be easily obtained.

The displacement function of the shell and also that of the stiffeners are extracted as functions of displacement of the shell's mid-plane surface (See Appendix A) [18, 19, 20, 21]. Thus, it is necessary to reach the displacement function of the shell's mid-plane surface. The displacement functions are two-variable functions and in this study, the method of separation of variables is applied to evaluating the displacement functions. Applying this method, the two-variable function is reduced to two single-variable functions in terms of " $\mathrm{x}$ " and "s", shell local coordinate axis. These single-variable functions are evaluated based on curve fitting of the results obtained through experiments or numerical analyses made on the main structure. In order to validate the results, first the obtained equivalent orthotropic shell is modelled using the ANSYS commercial FEM code [22] and then a modal analysis is performed on it. Finally the calculated mode shapes and natural frequencies are compared with those of the main stiffened shell. Figure 1 shows the flowchart of these steps. This method has been extended by the authors of this paper [23].

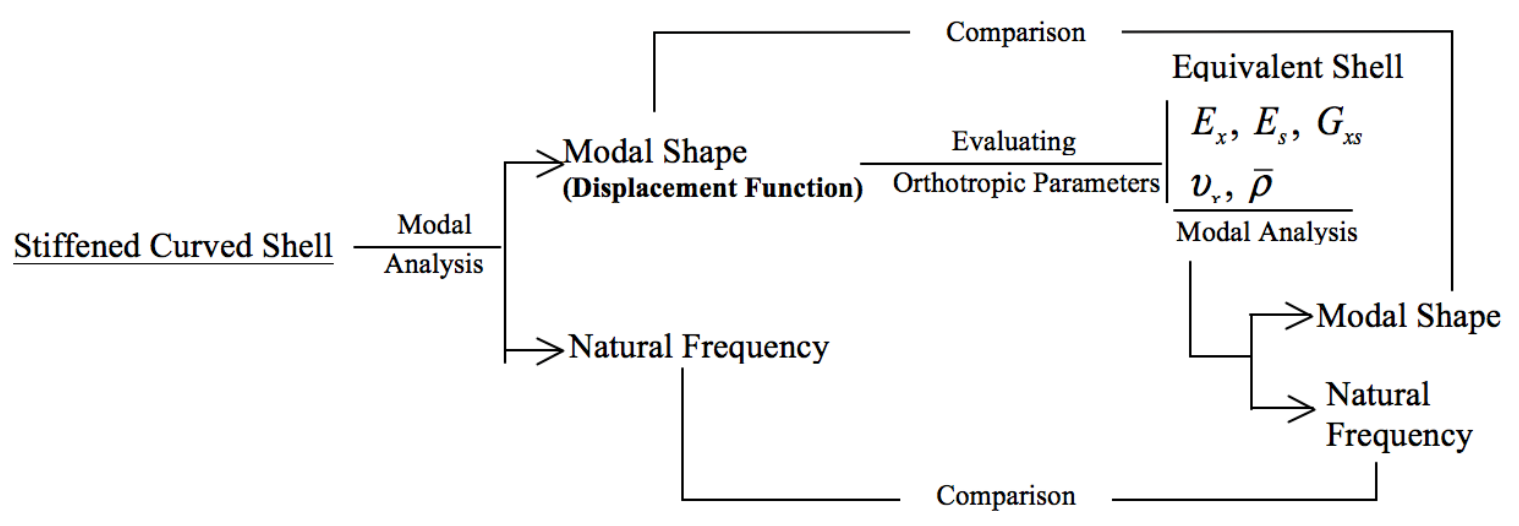

Figure 1 Flowchart of steps

The strain and kinetic energies for the stiffened curved shell and equivalent orthotropic shell are written as Eq. (1) and (2) respectively. More details about deriving these relations are given in Appendix B.

$$
\begin{aligned}
& U_{i s o}=U_{s h}+U_{l s} \\
& =\frac{1}{2}\left\{\begin{array}{l}
E\left[\frac{t_{p}^{3}}{12\left(1-v^{2}\right)} \operatorname{sh}(1)+A_{l s} L S(1)+I_{y y}^{l s} L S(2)\right]+\frac{E t_{p}^{3}}{12\left(1-v^{2}\right)} \operatorname{sh}(2) \\
+2 v D \operatorname{sh}(3)+G\left(\operatorname{sh}(4)+A_{l s} L S(3)\right)
\end{array}\right\}
\end{aligned}
$$




$$
\begin{gathered}
T_{i s o}=T_{s h}+T_{l s} \\
=\frac{1}{2} \rho\left(2 \pi f_{\text {iso }}\right)^{2}\left(t_{p} \operatorname{sh}(5)+A_{l s} L S(4)\right) \\
U_{o r}=\frac{1}{2}\left[D_{x} \operatorname{sh}(1)+D_{s} \operatorname{sh}(2)+2 v_{s} D_{x} \operatorname{sh}(3)+G_{x s} \operatorname{sh}(4)\right] \\
T_{o r}=\frac{1}{2} \rho_{o r} t_{p}\left(2 \pi f_{o r}\right)^{2} \operatorname{sh}(5)
\end{gathered}
$$

From the equality conditions between the corresponding energy relationships of the main stiffened shell structure (Eq. (1)) and equivalent unstiffened orthotropic shell structure (Eq. (2)), orthotropic shell parameters are extracted as bellow:

$$
\begin{gathered}
D_{x}=D+E\left(A_{l s} L S(1)+I_{y y}^{l s} L S(2)\right) / \operatorname{sh}(1) \\
D_{s}=D \\
v_{x}=v \\
G_{x s}=G\left(1+\frac{A_{l s} L S(3)}{s h(4)}\right) \\
\rho_{o r}=\rho\left(1+\frac{A_{l s} L S(4)}{s h(5)}\right)
\end{gathered}
$$

\section{FINITE ELEMENT MODEL}

The structures studied in this paper are divided into two general groups of stiffened and unstiffened plates. Two element categories of SHELL63 and BEAM44 were used for modelling the shell and stiffeners, respectively [22]. BEAM44 is a uniaxial element with tension, compression, torsion, and bending capabilities; andSHELL63 has both bending and membrane capabilities. Both in-plane and normal loads are permitted. Both elements have six degrees of freedom at each node: translations in the nodal $\mathrm{x}, \mathrm{y}$, and $\mathrm{z}$ directions and rotations about the nodal $\mathrm{x}, \mathrm{y}$, and $\mathrm{z}$-axes.

In order to model the boundary conditions of finite element models, the translation of the nodes related to four edges of the shell were fixed, while their rotation were left free. These boundary conditions are the prevailing conditions considered in studies on the vibration of local structures within ship hull girders. Figure 2 depicts a scheme of finite element parametric model. Such considerations 
as the dimensions of the model and stiffeners as well as the number of stiffeners should be taken into account when discretising the finite element model. Since local vibration modes of the stiffeners are ignored in the study of the global vibration modes of the structure, then there is no need for defining high degrees of freedom for the height of stiffeners in the modelling their local modes. For the reason and also for saving the time and costs of calculations, the element dimensions were so chosen in this study that there were 1 to 2 elements along the height of the stiffeners. As an example, the main geometric specifications and the degrees of freedom for three of finite element models out of the studied models are presented in Table 1.

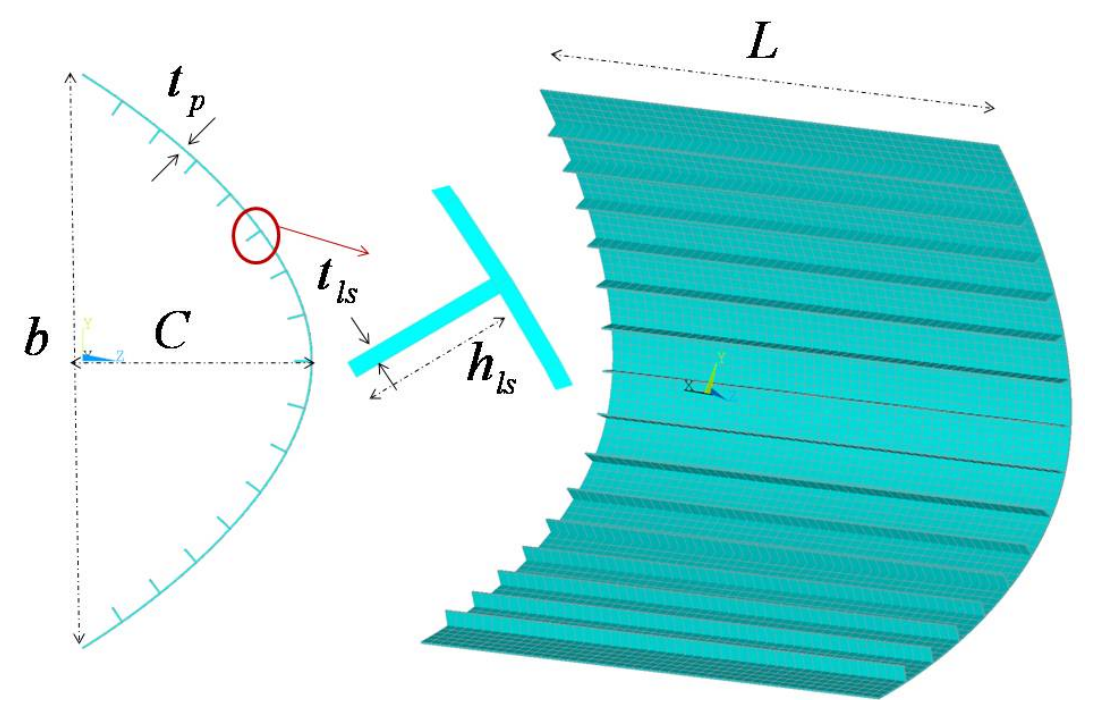

Figure 2 Parametric finite element model

Table 1 Geometrical properties of models adopted for free vibration and dynamic response analyses

\begin{tabular}{rrrrrc}
$\begin{array}{c}\boldsymbol{L} \\
{[\mathbf{m m}]}\end{array}$ & $\begin{array}{c}\boldsymbol{b} \\
{[\mathbf{m m}]}\end{array}$ & $\begin{array}{c}\boldsymbol{C} \\
{[\mathbf{m m}]}\end{array}$ & $\boldsymbol{h}_{l s}[\mathbf{m m}]$ & $\boldsymbol{n}_{\text {ls }}$ & $\begin{array}{c}\text { Number of } \\
\text { Degrees of } \\
\text { Freedom }\end{array}$ \\
\hline 4300 & 4300 & 1440 & 100 & 12 & 3756 \\
\hline 5600 & 5600 & 1400 & 100 & 10 & 4152 \\
\hline 7000 & 7000 & 1500 & 210 & 20 & 4512
\end{tabular}




\section{FREE VIBRATION ANALYSIS}

Natural frequency and mode shape are significant characteristics of a structure in free vibration. If these characteristics in stiffened and equivalent structures are equal, the stiffened structure can be replaced with the equivalent unstiffened that has more simplified governing equation in free vibration analysis. According to above-mentioned, in this study a number of different unidirectionally stiffened models are considered to the determine effectiveness of this method.

The geometrical characteristics of the models are given in Table 2 and the material is considered to be of normal strength steel type with $E=200[\mathrm{GPa}], v=0.3$ and $\rho=7800\left[\mathrm{Kg} / \mathrm{m}^{3}\right]$. Applying the developed method, equivalent orthotropic shell parameters are calculated (Table 3). The similarity between the first five natural frequencies as well as the mode shapes of the main stiffened shell and equivalent orthotropic shell is one of the important characteristics of this method. Table 4 shows the results of comparison between the main and equivalent structures from the natural frequency point of view. Also, in order to improve the quality of the judgment, a comparison between the mode shapes of the main stiffened shell and equivalent orthotropic shell structures is provided in Table 5 .

It is well understood that the developed method can be effectively employed in derivation of the equivalent orthotropic shell parameters with a reasonable level of accuracy. In spite of the fact that the equality of only the first natural frequency of both main structure and equivalent structure has been one of the conditions imposed in the developed method, it can be realised that a proper convergence trend exists among the other first five natural frequencies.

Table 2 Geometrical properties of models adopted for free vibration and dynamic response analysis

\begin{tabular}{cccccccc} 
ID & $\boldsymbol{L}[\mathbf{m m}]$ & $\boldsymbol{b}[\mathbf{m m}]$ & $\boldsymbol{C}[\mathbf{m m}]$ & $\boldsymbol{t}_{p}[\mathbf{m m}]$ & $\boldsymbol{h}_{l s}[\mathbf{m m}]$ & $\boldsymbol{t}_{l s}[\mathbf{m m}]$ & $\boldsymbol{n}_{l s}$ \\
\hline 1 & 4300 & 4300 & 1440 & 15 & 100 & 15 & 12 \\
\hline 2 & 5600 & 5600 & 1400 & 15 & 100 & 15 & 10 \\
\hline 3 & 7000 & 7000 & 1500 & 15 & 210 & 15 & 20 \\
\hline 4 & 5000 & 5000 & 2000 & 15 & 150 & 15 & 15
\end{tabular}


Table 3 Orthotropic shell parameters based on presented method

\begin{tabular}{cccccc}
$I D$ & $\boldsymbol{E}_{\boldsymbol{x}}[\mathrm{GPa}]$ & $\boldsymbol{E}_{\boldsymbol{s}}[\mathrm{Gpa}]$ & $\boldsymbol{G}_{\boldsymbol{x}}[\mathbf{G p a}]$ & $\boldsymbol{v}_{\boldsymbol{x}}$ & $\varrho_{\text {or }}\left[\mathbf{K g} / \mathbf{m}^{3}\right]$ \\
\hline 1 & 317 & 200 & 78.88 & 0.3 & 9783.16 \\
\hline 2 & 256 & 200 & 88.39 & 0.3 & 9202.08 \\
\hline 3 & 287 & 200 & 144.91 & 0.3 & 13358.89 \\
\hline 4 & 335 & 200 & 113.04 & 0.3 & 10075.61
\end{tabular}

Table 4 Comparison between the first four natural frequencies of the main stiffened shell and equivalent orthotropic shell structures [Htz]

\begin{tabular}{|c|c|c|c|c|c|c|}
\hline ID & Mode & 1 & 2 & 3 & 4 & 5 \\
\hline \multirow{3}{*}{1} & $f_{\text {iso }}$ & 43.71 & 47.25 & 49.58 & 55.93 & 74.32 \\
\hline & $f_{o r}$ & 44.11 & 46.49 & 52.07 & 57.03 & 68.19 \\
\hline & Error (\%) & 0.93 & 1.59 & 5.02 & 1.98 & 8.25 \\
\hline \multirow{3}{*}{2} & $f_{i s o}$ & 30.37 & 33.12 & 34.77 & 40.12 & 50.63 \\
\hline & $f_{o r}$ & 31.47 & 33.95 & 36.50 & 41.01 & 50.06 \\
\hline & Error (\%) & 3.60 & 2.49 & 4.97 & 2.21 & 1.12 \\
\hline \multirow{3}{*}{3} & $f_{i s o}$ & 20.51 & 21.57 & 23.49 & 25.56 & 32.50 \\
\hline & $f_{o r}$ & 20.38 & 20.44 & 24.19 & 25.36 & 31.02 \\
\hline & Error (\%) & 0.63 & 5.27 & 2.97 & 0.81 & 4.56 \\
\hline \multirow{3}{*}{4} & $f_{i s o}$ & 34.47 & 34.61 & 39.29 & 40.49 & 53.15 \\
\hline & $f_{o r}$ & 35.05 & 35.93 & 41.55 & 44.52 & 53.56 \\
\hline & Error (\%) & 1.69 & 3.80 & 5.75 & 9.95 & 0.78 \\
\hline
\end{tabular}


Table 5 Comparison between the modeshapes of the main stiffened shell and equivalent orthotropic shell structures

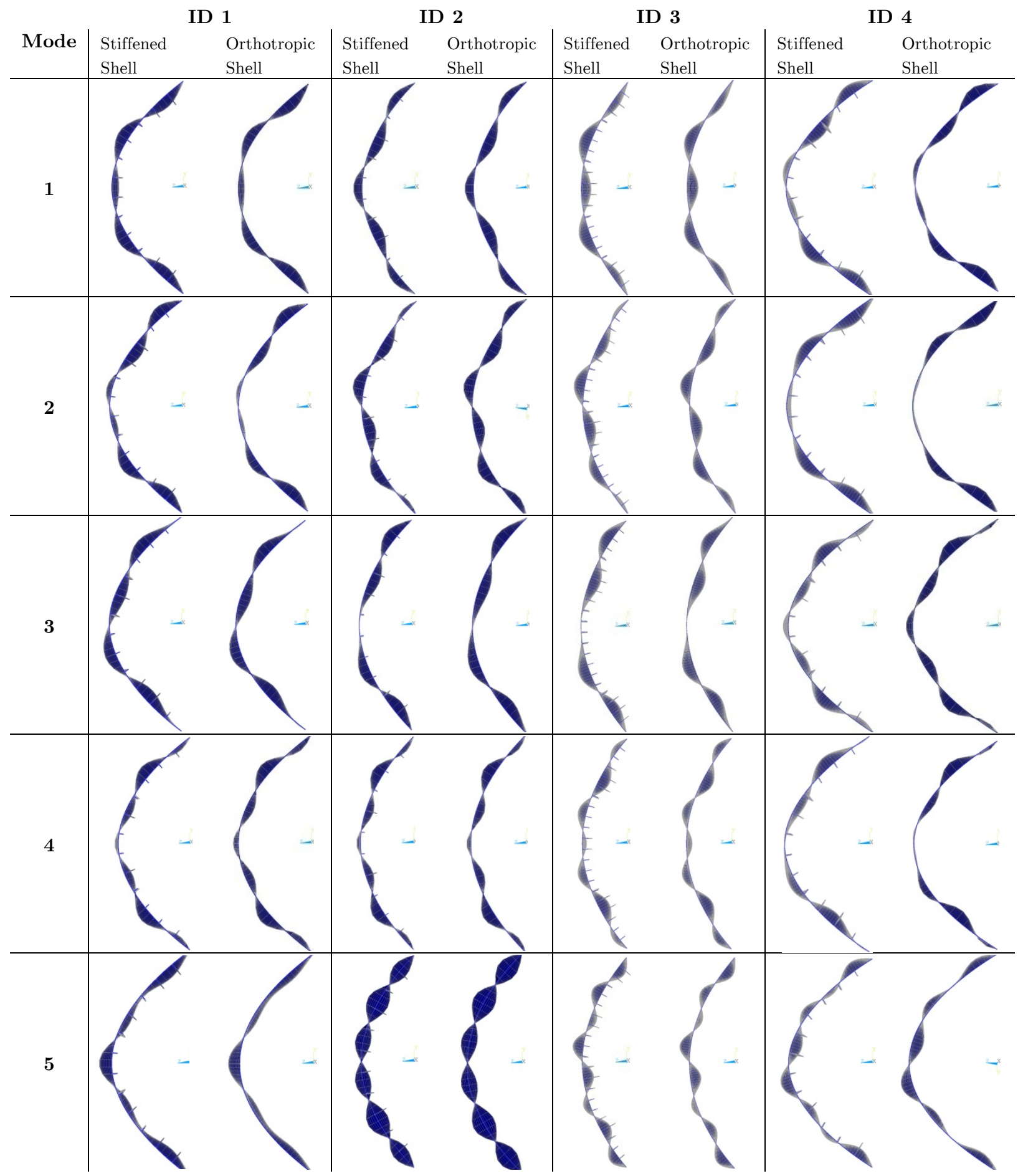




\section{DYNAMIC RESPONSE ANALYSIS}

Applying equivalent orthotropic shells in the dynamic response analysis causes considerable simplification in the governing equations of motion and provides the possibility of using analytical methods in their solution. It can be advantageous in dynamic analysis of complex structures such as ships where are subjected to vibration induced loads. Hence, the possibility of implementing the aforementioned method in dynamic response analysis is investigated in this study. A number of models with the geometric and mechanical properties as mentioned in Tables 2 and 3 are considered for this purpose.

Since shells having general curvatures are mostly located in ship's bow and stern structures and are subjected in impact loads such as slamming; these types of loads are considered in this study. A simplified model for this type of loads is illustrated in Figure 3. The pressure distribution is considered constant with respect to spatial variables $(\mathrm{x}, \mathrm{s})$. The intensity of this pressure is related to several factors and hydrodynamics analysis but in general it can be determined from ships' classifications rules as a function of ship geometry, general arrangement of the shell structure under study $\left[24,25,26\right.$ and 27]. In this study $P_{\text {Slamming }}=1[\mathrm{MPa}]$ is considered according to current slamming relations in the rules.

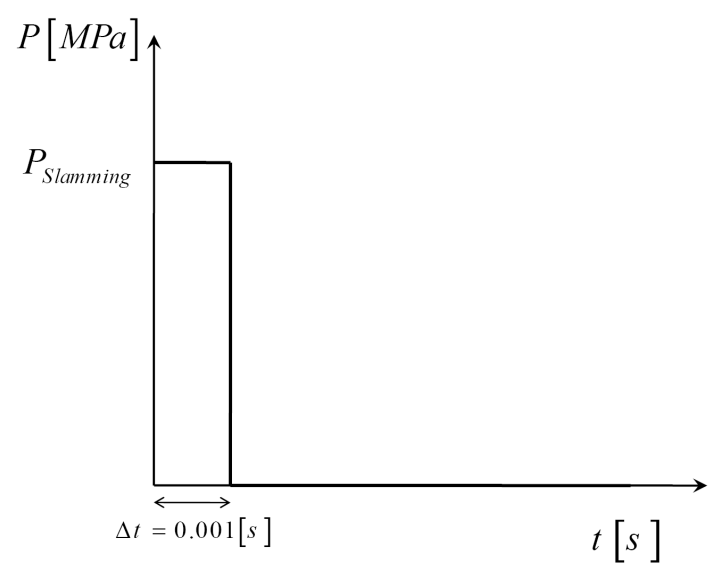

Figure 3 Simplifiedmodelforslammingpressuredistribution

Dynamics analysis has more aspects compared to modal analysis. In finite element model SHELL63 is applied for shell modeling as well as BEAM44 for stiffeners [22]. Stiffened and unstiffened finite element models are exactly the same from the viewpoints of geometry, boundary and load conditions. The material properties in the models for dynamic response analysis are similar to those in the modal analysis as listed in Table 3.

The mode summation method is applied in order to make comparisons between dynamic responses of stiffened shells and their equivalent orthotropic shells. In this method, the numbers of elements has to be sufficient enough to model higher desired number of mode shapes and time interval in sub-steps $\Delta t$ should be less or equal to $1 /\left(20 \cdot f_{\max }\right)$. 
In this study, the time-normal displacement diagrams in both the main structure and its equivalent structure are extracted at the same nodes and compared with each other in order to assess the accuracy level. The response functions in the mode summation method are assumed as finite series of the vibration mode shapes. This means that the more the number of modes participated in the solution, the more exact the results of dynamic response analysis would be. This is just true from theoretical point of view but in real practice, increasing the number of mode shapes leads to growing the costs and therefore, it is necessary to perform a sensitive analysis in order to find out the minimum required mode numbers to achieve dynamic response estimations with appropriate degrees of accuracy. A sample of this analysis is performed for model ID01. As seen in Figure 4, assuming the number of modes (NOM) to be equal to or above than five, has the same effects on the dynamic response and thus, the desirable minimum number of modes (NOM) is taken to be equal to 5. It means that with assuming the first five vibration modes for the structures under consideration in the present study, their dynamic responses can be evaluated with suitable accuracy levels.

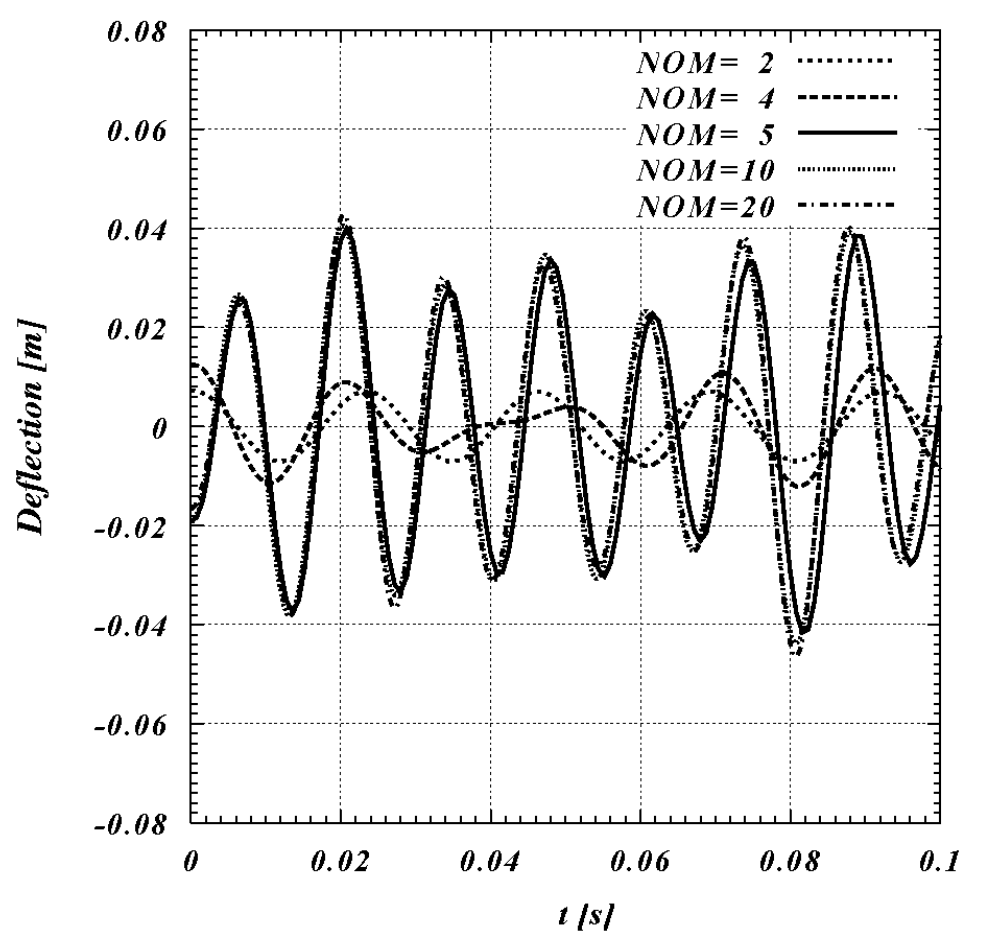

Figure 4 Sensitive analysis on the number of modes (NOM) used in mode summation method

According to the results shown in Tables 4 and 5 and also Figure 4, it can be expected that the dynamic response of the original stiffened structure is the same as that of the equivalent orthotropic un-stiffened structure. Thus, the behavior of the main stiffened structure can be identified using the behavior of the equivalent orthotropic structure with an acceptable level of accuracy. This matter is confirmed easily based on the results shown in Figures 5 to 8 and its importance can be realized by looking at the simple governing equations for the equivalent orthotropic structure in comparison with those governing equations for the original stiffened structure. 


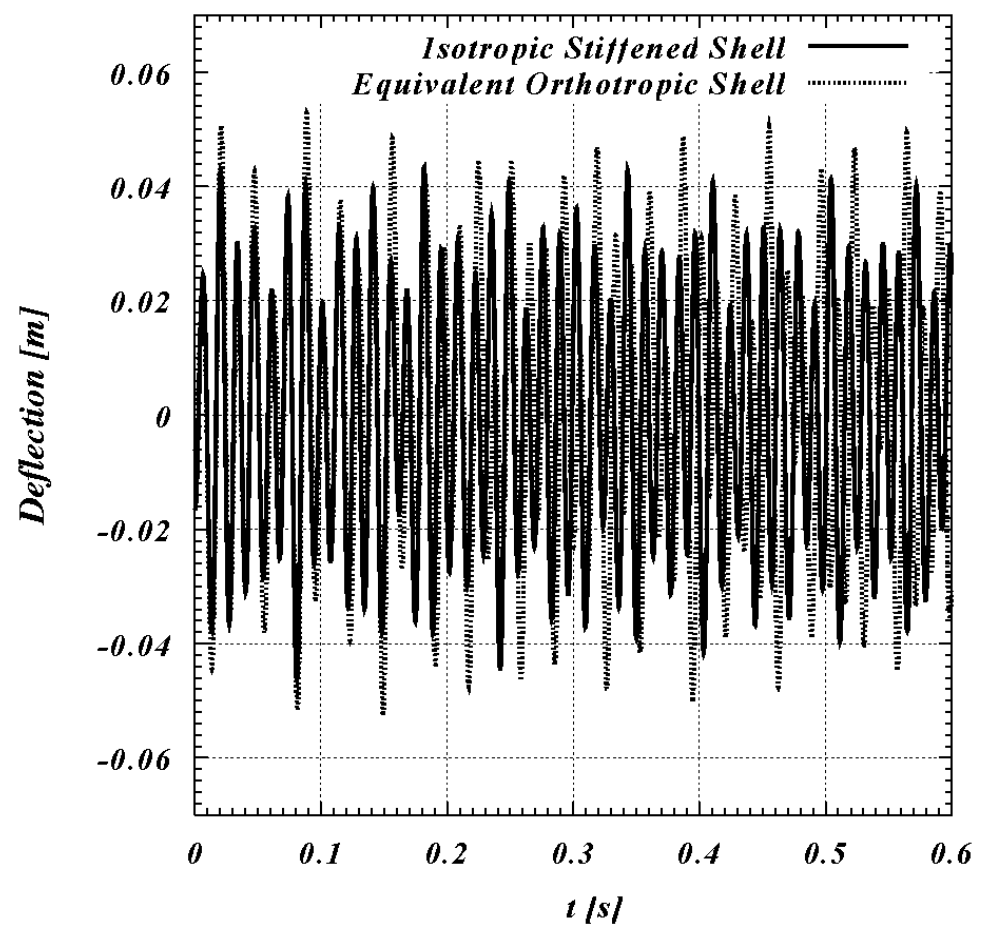

Figure 5 Comparison of deflection-time diagrams for stiffened and equivalent shells for the case of ID01 model

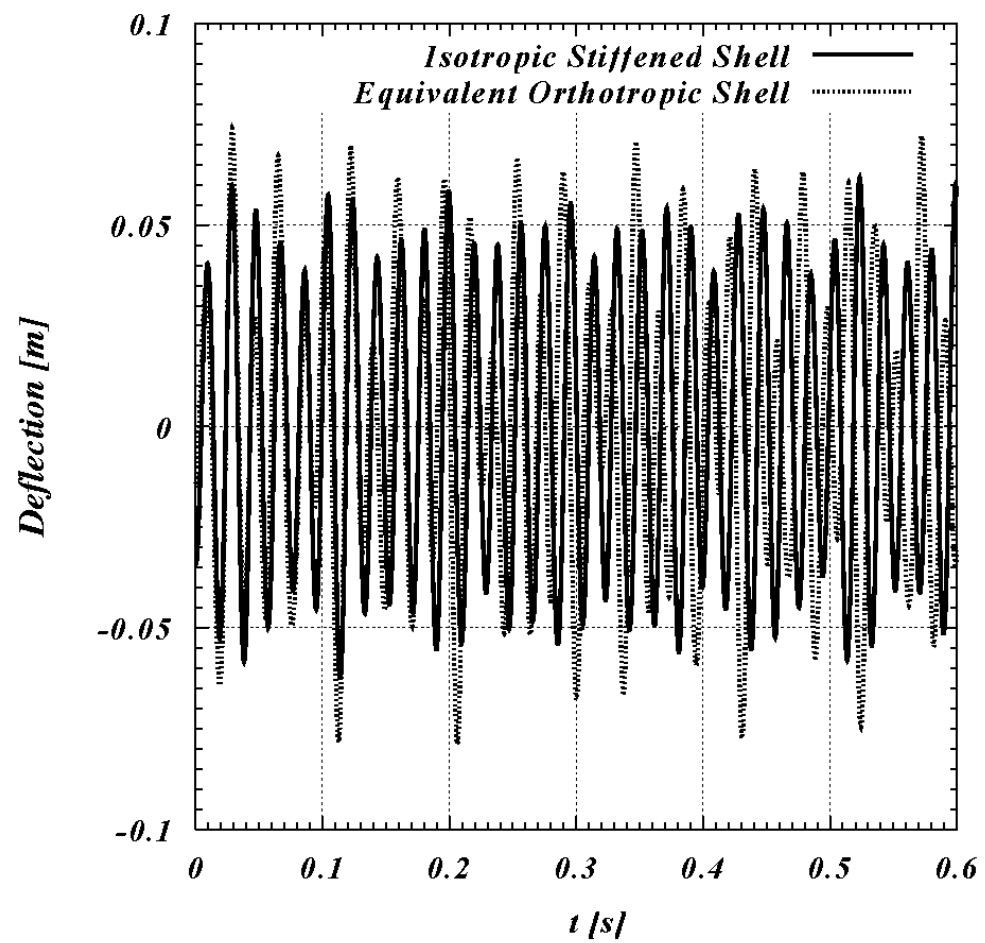

Figure 6 Comparison of deflection-time diagrams for stiffened and equivalent shells for the case of ID02 model 


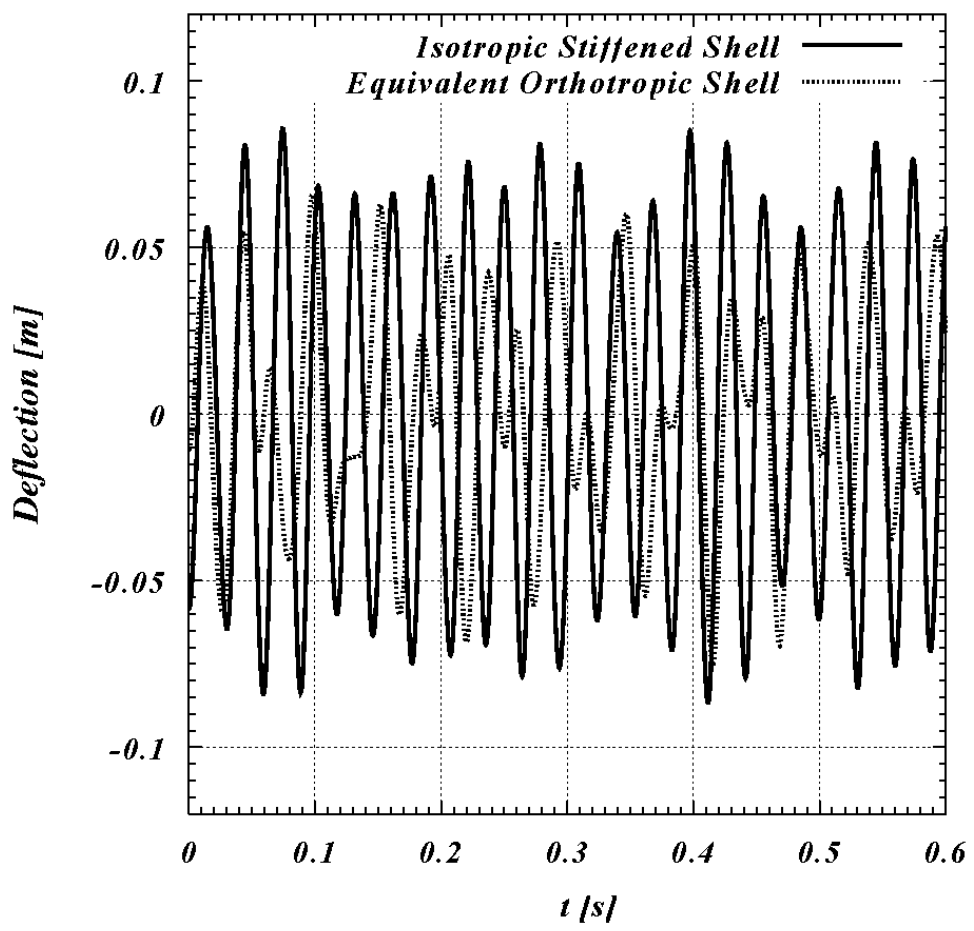

Figure 7 Comparison of deflection-time diagrams for stiffened and equivalent shells for the case of ID03 model

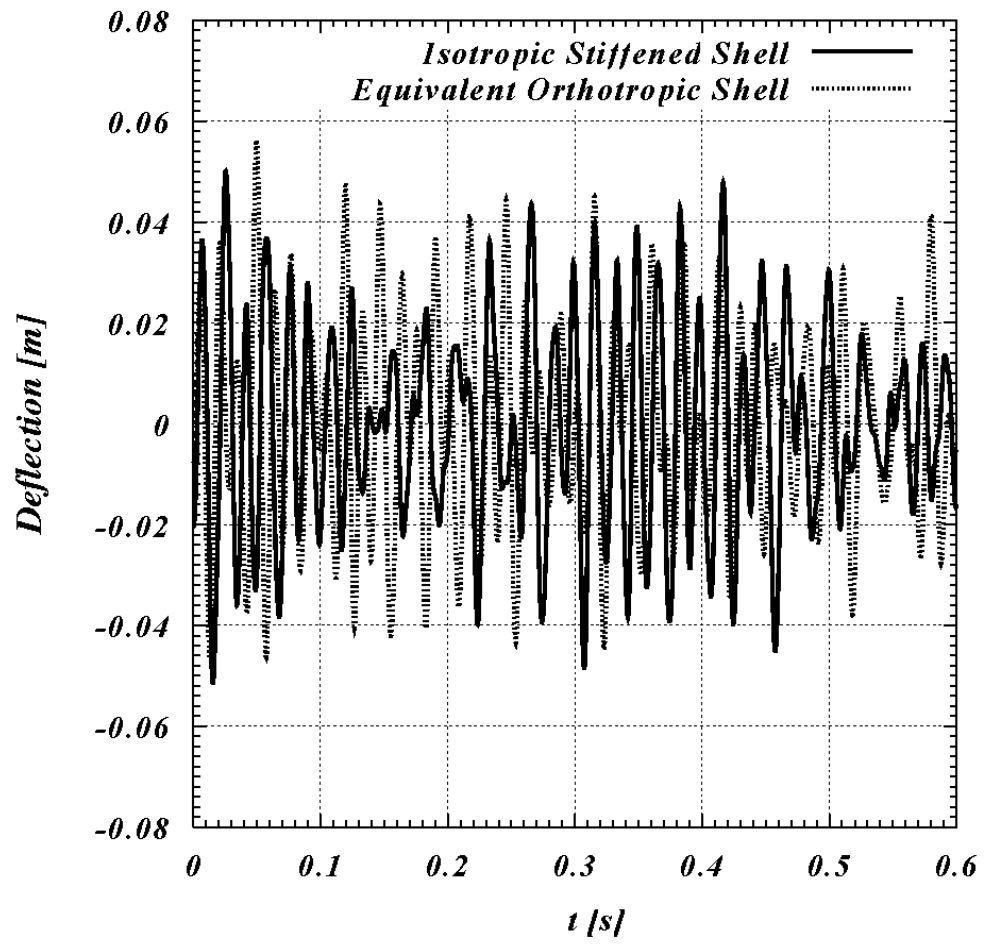

Figure 8 Comparison of deflection-time diagrams for stiffened and equivalent shells for the case of ID04 model 
Deflection-time diagrams shown in Figures 5 to 8 and also geometrical properties of the models given in Table 2, reveal the fact that when dimensions of stiffeners in comparison with those of the shell are large, there would be some difference between dynamic responses of the main and equivalent structures. Such a difference is mainly due to presence of concentrated masses at the location of stiffeners in the main structures, which are simplified with added uniform distributed masses in equivalent structures.

When a similar material is being used for both stiffeners and the shell itself, the increase in lumped mass through increasing the dimensions and the number of stiffeners is concurrently followed by the increase in the structural stiffness. The increase in structural stiffness is, in practice, accompanied with the increase in lumped mass since the arrangement of the stiffeners must have a specific pattern considering the structural considerations and the constraints imposed on the structure. For example, it is impossible to use a shell with a higher number of stiffeners having lower web heights to produce an exactly equivalent situation to another shell that is stiffened with a lower number of stiffeners but possessing higher web heights.

Nevertheless, the errors in using this method is negligible compared to its advantages in simplifying equations of the motion and improving abilities in solution of complex problems.

\section{CONCLUSIONS}

Free vibration and dynamic response of the cylindrical stiffened shells with a parabolic type of curvature, as are being used in typical marine structures, were investigated in this study. The main outcome of the research can be concluded as follows:

- An energy-based algorithm was developed in order to find out the mechanical properties of the orthotropic shells having the parabolic curvature that is taken equivalent to the original unidirectionally stiffened shells with the same parabolic curvature.

- Similarity of the mode shapes and equality of the natural frequencies were strictly taken as the main governing conditions in derivation of equivalent orthotropic shell parameters.

- Although the above conditions were made when obtaining the equivalent orthotropic shell parameters, a relatively good agreement was observed between the first five natural frequencies corresponding to the original stiffened curved shell as well as its equivalent unstiffened curved shell.

- As a result of sensitive analysis, applying first five mode shapes is sufficient to predict the dynamic response of the structures in mode summation method.

- Dynamic analysis was performed on stiffened and equivalent shells under the impact loading conditions and acceptable agreement was observed between their dynamic responses.

Implementation of orthotropic equivalent shell can be considered as suitable and acceptable method to vibration analysis of complex structures such as ships.

Latin American Journal of Solids and Structures 10(2013) $747-766$ 


\section{References}

[1] K. T. Sundara Raja Iyengar and R. Narayana Iyengar. Determination of the orthotropic plate parameters of stiffened plates and grillages in free vibration, J Applied Scientific Research, 17(6):422-438, 1967.

[2] M. S. Troitsky. Stiffened Plates Bending Stability and Vibration. Elsevier Scientific Publishing Co, 1976.

[3] R. Szilard, Theories and Applications of Plate Analysis, John Wiley and Sons, Hoboken, NJ, 2004.

[4] H. Xu, J. Du, W. L. Li. Vibrations of rectangular plates reinforced by any number of beams of arbitrary lengths and placement angles. Journal of Sound and Vibration, 329:3759-3779, 2010.

[5] Yu Luan, M. Ohlrich, F. Jacobsen. Improvements of the smearing technique for cross-stiffened thin rectangular plates. Journal of Sound and Vibration, 330:4274-4286, 2011.

[6] C. Omd'varan. Free vibration of grid-stiffened plates. Journal of Sound and Vibration. 19(4):463-472, 1971.

[7] A. Deb, M. K. Deb, M. Botoon. Analysis of orthotropically modeled stiffened plates. Journal of Solids Structures, 27(5):647-664, 1991.

[8] MikulasJr MM, McElman JA. On the free vibration of eccentrically stiffened cylindrical shells and plates. NASA TN-D 3010, 1965.

[9] Ruotolo R. A comparison of some thin shell theories used for the dynamic analysis of stiffened cylinders. Journal of Sound and Vibration. 243(5):847-860, 2001.

[10] B. A. J. Mustafa, R. Ali. An Energy method for free vibration analysis of stiffened circular cylindrical shells. Computers \& Structures, 32(2):355-363, 1989.

[11] X. Zhao, K. M. Liew, T.Y. Ng. Vibration of rotating cross-ply laminated circular cylindrical shells with stringer and ring stiffeners. International Journal of Solids Structures, 39:529-545, 2002.

[12] A. A. Jafari, M. Bagheri. Free vibration of non-uniformly ring stiffened cylindrical shells using analytical, experimental and numerical methods. Thin-Walled Structures, 44:82-90, 2006.

[13] Zhi Pan, Xuebin Li, Janjun Ma. A study on free vibration of a ring-stiffened thin circular cylindrical shell with arbitrary boundary conditions. Journal of Sound and Vibration, 314:330-342, 2008.

[14] Lin Gan, Xuebin Li, Zheng Zhang. Free vibration analysis of ring-stiffened cylindrical shells using wave propagation approach. Journal of Sound and Vibration, 326:633-646, 2009.

[15] Sh. Torkamani, H. M. Navazi, A. A. Jafari, M. Bagheri. Structural similitude in free vibration of orthogonally stiffened cylindrical shells. Thin-Walled Structures, 47:1316-1330, 2009.

[16] R.S. Srinivasan, P.A. Krishnan. Dynamic analysis of stiffened conical shell panels. Computers \& Structures, 33(3):831-837, 1989.

[17] Yu Luan, MogensOhlrich, Finn Jacobsen. Smearing technique for vibration analysis of simply supported crossstiffened and doubly curved thin rectangular shells. Joutnal of Acoustial Society of America, 129(2):707-716, 2010.

[18] Arthur Leissa, Vibration of Shells, Acoustical Society of America, 1993.

[19] I. S. Sokolnikoff, Mathematical Theory of Elasticity, McGRAw-HILL Book Company Inc., 1946.

[20] Philippe G. Ciarlet, Mathematical Elasticity, Vol3: Theory of shells, Elsevier Science B. V., 2000.

[21] Werner Soedel, Vibrations of Shells and Plates, Marcel Dekker, Inc., Third edition, 2005.

[22] ANSYS $^{\circledR}$, Online Manuals, United States of America: ANSYS Inc. Release 11.0: 2007.

[23] P. Edalat, M. R. Khedmati, C. G. Soares. Determination of Equivalent Orthotropic Shell Parameters for Free Vibration Analysis of Stiffened Shells with Parabolic Curvature. Submitted to Thin-Walled Structure.

[24] American Bureau of Shipping. Rules for building and classing steel ships. Pt. 5, Ch. 3, Section 3, 2003.

[25] Det Norske Veritas. Rules for classification of ships, Pt. 3, Ch. 1, Section 6H, 2003.

[26] Bureau Veritas. Rules for classification of steel ships, Pt. B, Ch. 9, Section 1, 2007.

[27] Lloyd's Register of Shipping. Rules and Regulations for the classification of ships, Pt. 3, Ch. 5, 2000. 


\section{Appendix A}

Governing geometrical and elasticity relationships for cylindrical shell element with parabolic curvature:

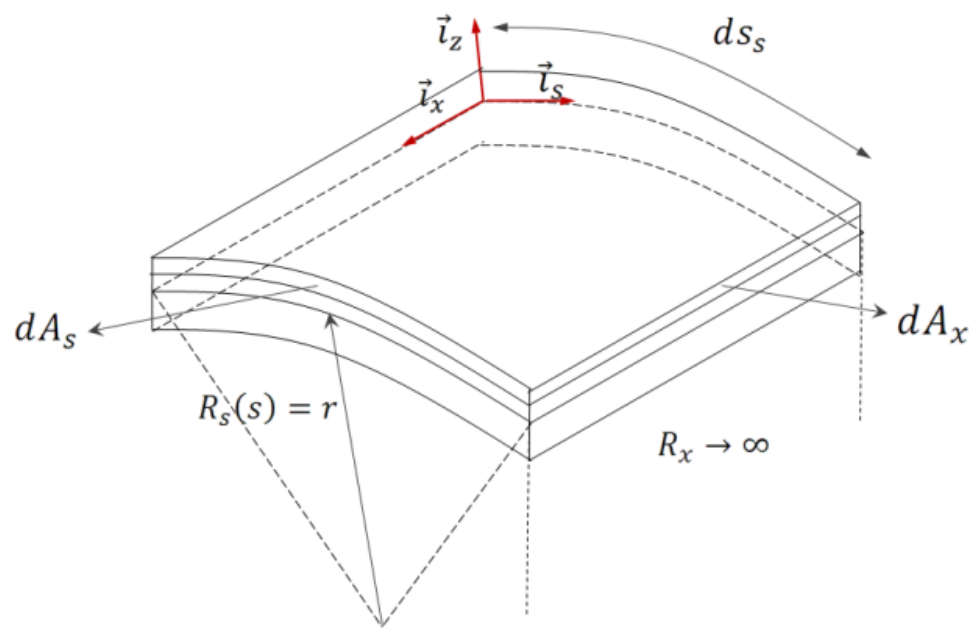

Figure A1 An element of cylindrical parabolic shell

\section{Geometrical Properties:}

$$
\begin{aligned}
& R_{x} \rightarrow \infty \\
& d s_{s}(z)=(1+z / r) d s \\
& d A_{x}(z)=d x d s
\end{aligned}
$$

Displacement functions: (satisfying the Kirchhoff hypothesis)

$$
\begin{array}{lll}
U(x, s, z)=u(x, s, z)+z \theta_{x}(x, s) & & \text { (A2.a) } \\
V(x, s, z)=v(x, s, z)+z \theta_{s}(x, s) & \text { (A2.b) } & W(x, s, z)=w(x, s, z)
\end{array}
$$

Strain-displacement relations: (General relations)
$e_{x}=U_{, x}$
$e_{s}=V_{, s}+W / r$
$e_{z}=W_{, z}$
$\gamma_{x s}=U_{, s}+V_{, x}$
$\gamma_{x z}=W_{, x}+U_{, z}$
$\gamma_{s z}=W_{, s}+V_{, z}$ 
Rotation functions: Based on the Love's first approximation in order to satisfy the thin shell theory and Kirchhoff's hypothesis, the shear strains $\gamma_{x z}$ and $\gamma_{s z}$ are neglected. Hence:

$$
\theta_{x}(x, s)=-w_{, x} \quad(\text { A } 4 . \mathrm{a}) \quad \theta_{s}(x, s)=v / r-w_{, s}
$$

Strain-displacement relations: (In terms of the shell mid-plane displacement function)

$$
\begin{array}{lll}
e_{x}=u_{, x}-z w_{, x x} & \text { (A5.a) } & e_{s}=v_{s}+\frac{w}{r}+z\left((v / r)_{s}-w_{s s}\right) \\
\gamma_{x s}=u_{, s}+v_{, x}-2 z w_{, x s}+2 z v_{, x} / r & \text { (A5.c) }
\end{array}
$$

Stress-strain relationship: (For the general case of orthotropic material)

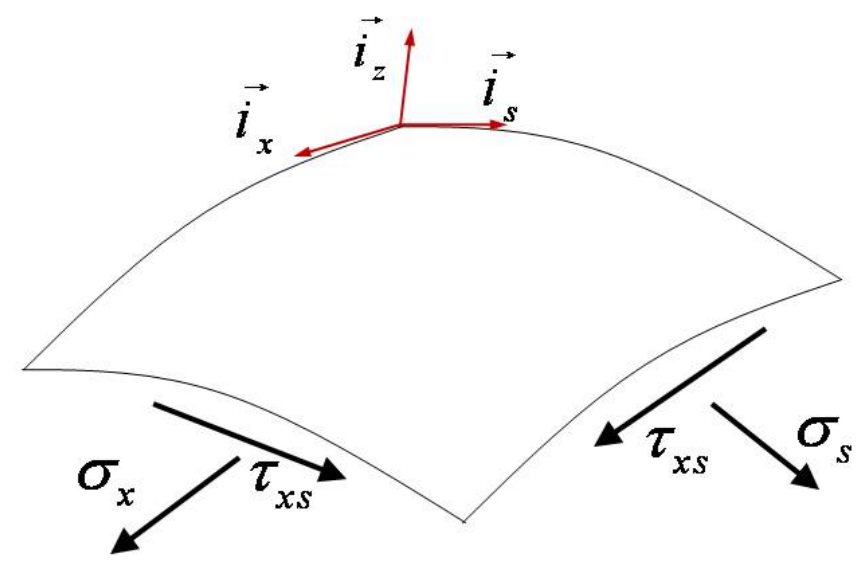

Figure A2 Stress components on the mid-plane of shell element

$$
\begin{array}{lll}
\sigma_{x}=\frac{1}{1-v_{x} v_{s}}\left(E_{x} e_{x}+v_{x} E_{s} e_{s}\right) & \text { (A6.a) } & \sigma_{s}=\frac{1}{1-v_{x} v_{s}}\left(E_{s} e_{s}+v_{s} E_{x} e_{x}\right) \\
\tau_{x s}=G_{x s} \gamma_{x s} & \text { (A6.c) }
\end{array}
$$

Governing geometrical and elasticity relationships for longitudinal stiffener element: 


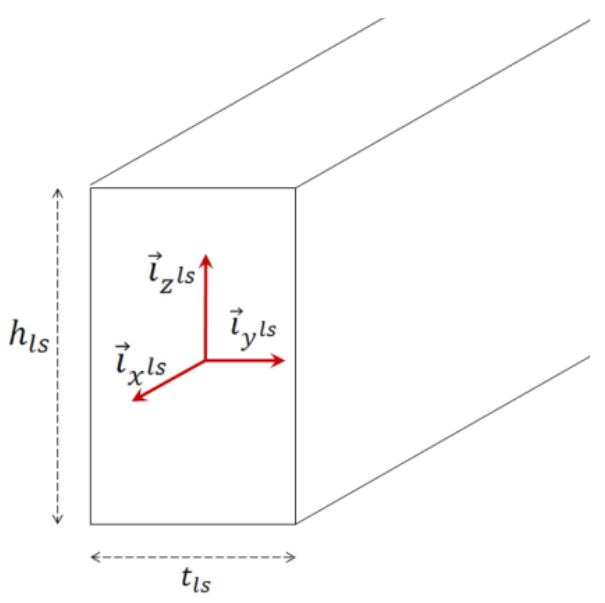

Figure A3 Longitudinal stiffener element

Relation between the displacement of the stiffeners and displacement of the shell:
$u^{l s}=u+e_{l s} w_{, x}$
$v^{l s}=v+e_{l s}\left(w_{, s}-v / r\right)$
$w^{l s}=w$

Where the magnitude of the variable $e_{l s}$ depended on the arrangement of the longitudinal stiffeners is

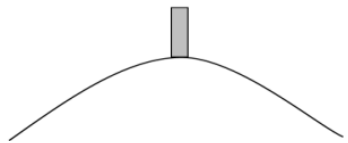

External Stiffener

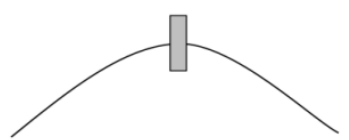

Central Stiffener

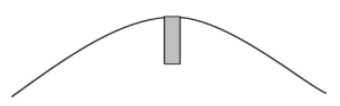

Internal Stiffener

Figure A4 Longitudinal stiffener arrangement in shell

$\begin{array}{lllll}e_{l s}=-\left(t_{p}+h_{l s}\right) / 2 & \text { External Stiffener } & \text { (A8.a) } & e_{l s}=0 & \text { Central Stiffener } \\ e_{l s}=\left(t_{p}+h_{l s}\right) / 2 & \text { Internal Stiffener } & \text { (A8.c) } & & \end{array}$

Strain-displacement relations:

$$
\begin{array}{lll}
e_{x}^{l s}=u_{, x}+\left(e_{l s}-z^{l s}\right) w_{, x x} & \text { (A9.a) } & e_{s}^{l s}=0 \\
\gamma_{x s}^{l s}=v_{, x}+e_{l s}\left(w_{, x s}-v_{, x} / r\right) & \text { (A9.c) } &
\end{array}
$$

Stress-strain relationship: (The effect of the Poisson's ratio is neglected)

$$
\sigma_{x}^{l s}=E e_{x}^{l s} \quad \text { (A10.a) } \quad \sigma_{s}^{l s}=0
$$




$$
\tau_{x s}^{l s}=E \gamma_{x s}^{l s} / 2
$$

\section{Appendix B}

The general well known energy expression in elastic materials is

$$
U_{*}=\frac{1}{2} \int\left(\sigma_{x} e_{x}+\sigma_{s} e_{s}+\tau_{x s} \gamma_{x s}\right) d V \quad(\mathrm{~B} 1 . \mathrm{a}) \quad T=\frac{1}{2} \int\left(U_{, t}^{2}+V_{, t}^{2}+W_{, t}^{2}\right) d V \quad \text { (B1. b) }
$$

The energy expression for any structural element is derived after substitution of its corresponding geometrical and elasticity relationships from appendix A into above equations and taking integration over the whole element volume. These expressions are as follow:

\section{Orthotropic Shell}

$$
\begin{aligned}
& U_{o r}=\frac{1}{2}\left[D_{x} \operatorname{sh}(1)+D_{s} \operatorname{sh}(2)+2 v_{s} D_{x} \operatorname{sh}(3)+G_{x s} \operatorname{sh}(4)\right] \\
& T_{o r}=\frac{1}{2} \rho_{o r} t_{p}\left(2 \pi f_{o r}\right)^{2} \operatorname{sh}(5)
\end{aligned}
$$

\section{Isotropic Shell}

$$
\begin{aligned}
& U_{s h}=\frac{1}{2}\{D[\operatorname{sh}(1)+\operatorname{sh}(2)]+2 v D \operatorname{sh}(3)+G \operatorname{sh}(4)\} \\
& T_{s h}=\frac{1}{2} \rho t_{p}\left(2 \pi f_{i s o}\right)^{2} \operatorname{sh}(5)
\end{aligned}
$$

\section{Longitudinal Stiffeners}

$$
\begin{aligned}
& U_{l s}=\frac{E}{2}\left[A_{l s} L S(1)+I_{y y}^{l s} L S(2)\right]+\frac{G}{2} A_{l s} L S(3) \\
& T_{l s}=\frac{1}{2} \rho A_{l s}\left(2 \pi f_{i s o}\right)^{2} L S(4)
\end{aligned}
$$

Where the coefficients sh(i) and LS(i) are:

$$
\operatorname{sh}(1)=\int_{0}^{S} \int_{0}^{L}\left(\frac{12}{t_{p}^{2}} u_{, x}^{2}+w_{, x x}^{2}-2 \frac{u_{, x} w_{, x x}}{r}\right) d x d s
$$




$$
\begin{aligned}
& \operatorname{sh}(2)=\int_{0}^{S} \int_{0}^{L}\left(\frac{12}{t_{p}^{2}}\left(v_{s,}+\frac{w}{r}\right)^{2}+\left(w_{, s s}-\left(\frac{v}{r}\right)_{, s}\right)^{2}+2\left(\frac{v_{, s}}{r}+\frac{w}{r^{2}}\right)\left(\left(\frac{v}{r}\right)_{, s}-w_{, s s}\right)\right) d x d s \\
& \operatorname{sh}(3)=\int_{0}^{S} \int_{0}^{L}\left(\left(\frac{12}{t_{p}^{2}} u_{, s}-\frac{w_{, x x}}{r}\right)\left(v_{, s}+\frac{w}{r}\right)+\left(w_{, x x}-\frac{u_{, x}}{r}\right)\left(w_{, s s}-\left(\frac{v}{r}\right)_{, s}\right)\right) d x d s \\
& \operatorname{sh}(4)=\int_{0}^{S} \int_{0}^{L}\left(t_{p}\left(u_{, s}+v_{, x}\right)^{2}+\frac{t_{p}^{3}}{3}\left(\frac{v_{, x}}{r}-w_{, x s}\right)^{2}+\frac{t_{p}^{3}}{3 r}\left(u_{, s}+v_{, x}\right)\left(\frac{v_{, x}}{r}-w_{, x s}\right)\right) d x d s \\
& \operatorname{sh}(5)=\int_{0}^{t_{p}} \int_{0}^{S} \int_{0}^{L}\left(\left(u-z \mathrm{~W}_{, x}\right)^{2}+\left(v+z\left(\frac{v}{r}-\mathrm{w}_{, s}\right)\right)^{2}+w^{2}\right) d x d s d z
\end{aligned}
$$

And

$$
\begin{aligned}
& L S(i)=\sum_{j=1}^{n_{l s}} L S(i)_{j} \quad \text { at } s=s_{j} \\
& L S(1)_{j}=\int_{0}^{L}\left(u_{, x}+e_{l s} w_{, x x}\right)^{2} d x \\
& L S(2)_{j}=\int_{0}^{L} w_{, x x}^{2} d x \\
& L S(3)_{j}=\int_{0}^{L}\left(v_{, x}+e_{l s} w_{, x s}\right)^{2} d x \\
& L S(4)_{j}=\int_{0}^{L}\left[\left(u+e_{l s} w_{, x}\right)^{2}+\left(v+e_{l s}\left(w_{, s}-\frac{v}{r}\right)\right)^{2}+w^{2}\right] d x
\end{aligned}
$$

